\title{
Effects of glycopyrrolate premedication on preventing postoperative catheter-related bladder discomfort in patients receiving ureteroscopic removal of ureter stone
}

\author{
Jin A Kim, Jin Hye Min, Hong Sik Lee, Hyong Rae Jo, Ui Jin Je, and \\ Jin Hyub Paek \\ Department of Anesthesiology and Pain Medicine, Myongji Hospital, Seonam University College of Medicine, \\ Goyang, Korea
}

\begin{abstract}
Background: Glycopyrrolate given as reversing agents of muscle relaxants has been reported to be effective in reducing postoperative catheter-related bladder discomfort (CRBD). However, it remains unclear whether glycopyrrolate as premedication is also effective. This study aims to investigate the effectiveness of glycopyrrolate as premedication on preventing CRBD in the post-anesthesia care unit (PACU).

Methods: Eighty-three patients who received elective ureteroscopic removal of ureteral stone were randomly assigned to the control $(n=43)$ or the glycopyrrolate group $(n=40)$. The glycopyrrolate group was treated with glycopyrrolate 0.3 $\mathrm{mg}$ as premedication while the control group received $0.9 \%$ saline $1.5 \mathrm{ml}$. The incidence and severity of CRBD and pain score using numerical rating scale (NRS) were measured in the PACU.

Results: The incidence of CRBD ( 26 of 40 patients vs. 41 of 43 patients, relative risk [RR] $=0.68,95 \%$ Confidence interval $[\mathrm{CI}]=0.53-0.86, \mathrm{P}=0.001$ ) and the moderate to severe CRBD incidence ( 6 of 40 patients vs. 20 of 43 patients, $\mathrm{RR}=$ $0.32,95 \% \mathrm{CI}=0.14-0.72, \mathrm{P}=0.002)$ were lower in the glycopyrrolate group than in the control group. Also, postoperative pain NRS score was found to be lower in the glycopyrrolate group (median $=1[\mathrm{Q} 1=0, \mathrm{Q} 3=2]$ ) compared to the control group $(3[1,5]$, median difference $=1.00,95 \% \mathrm{CI}=0.00-2.00, \mathrm{P}=0.002)$.

Conclusions: The use of glycopyrrolate $0.3 \mathrm{mg}$ as premedication in patients receiving ureteroscopic removal of ureteral stone reduced the incidence and severity of CRBD, and decreased postoperative pain in the PACU.
\end{abstract}

Key Words: Complications, Glycopyrrolate, Ureteroscopy, Urinary catheterization.

Corresponding author: Jin Hye Min, M.D., Ph.D.

Department of Anesthesiology and Pain Medicine, Myongji Hospital, Seonam University College of Medicine, 55, Hwasu-ro 14beon-gil, Deogyang-gu, Goyang 10475, Korea

Tel: 82-31-810-6200 , Fax: 82-31-810-5109, Email: jhmin@mjh.or.kr

ORCID: http://orcid.org/0000-0002-0259-6501

Received: June 20, 2016. Revised: June 31, 2016 (1st); August 29, 2016 (2nd); September 12, 2016 (3rd). Accepted: September $12,2016$.

Korean J Anesthesiol 2016 December 69(6): 563-567

https://doi.org/10.4097/kjae.2016.69.6.563

(c) This is an open-access article distributed under the terms of the Creative Commons Attribution Non-Commercial License (http://creativecommons.org/ licenses/by-nc/4.0/), which permits unrestricted non-commercial use, distribution, and reproduction in any medium, provided the original work is properly cited. 


\section{Introduction}

Catheter-related bladder discomfort (CRBD), in which affected patients complain of symptoms such as a burning sensation in the suprapubic area and urge to void due to stimulation by the catheter [1], generally occurs in about $58-80 \%$ of patients with a urethral catheter [2-5]. In post-anesthesia care unit (PACU), CRBD is one of the risk factors for the occurrence of emergence agitation [6].

Glycopyrrolate, a drug commonly used with a cholinesterase inhibitor to reverse muscle relaxants, is effective in reducing postoperative CRBD, according to Kim et al. [7]. Sugammadex, recently introduced as a substitutional reversing agent of muscle relaxants is very useful in shorterm operations such as ureteroscopic removal of ureteral stone. In this case, glycopyrrolate would be omitted, and no reduction in postoperative CRBD would be expected [7]. This study attempted to investigate the effects of glycopyrrolate as premedication on CRBD. We hypothesized that glycopyrrolate premedication would reduce the incidence of postoperative CRBD.

\section{Materials and Methods}

After receiving approval from the Institutional Review Board of the hospital and written consents from the patients, a prospective, randomized, double-blind, placebo-controlled study was conducted. The patients were of age 18 to 70 and consisted of American Society of Anesthesiologists physical status I and II, who were scheduled to receiving elective ureteroscopic removal of ureter stone and ureteral stent insertion from November 2015 to April 2016. Exclusion criteria were bladder outflow obstruction, overactive bladder (frequency greater than three times per night or more than eight times per $24 \mathrm{~h}$ ), chronic kidney disease (serum creatinine $>1.6 \mathrm{mg} / \mathrm{dl}$ ), chronic use of medication with anticholinergic effect (e.g., dimenhydrinate, tricyclic antidepressant), initial heart rate $>100$ beats/min, asthma, morbid obesity (body mass index $>30 \mathrm{~kg} / \mathrm{m}^{2}$ ), arrhythmia, heart failure, and psychiatric disease. Patients with intraoperative anti-muscarinic drugs administration and without ureteral stent or urethral catheter during operation were also excluded from the study.

All patients were allocated into either the control or glycopyrrolate group using a computer-generated random number table. The glycopyrrolate group received glycopyrrolate $0.3 \mathrm{mg}$ intravenously (IV) as premedication before induction [8,9], while the control group received $0.9 \%$ saline $1.5 \mathrm{ml}$ using unlabeled syringes for double blind. Anesthesia was induced with propofol 2 $\mathrm{mg} / \mathrm{kg}$ and a laryngeal mask airway (LMA, I-gel ${ }^{\mathrm{TM}}$, Intersurgical Ltd., Wokingham, Berkshire, UK) was inserted after administration of rocuronium bromide $0.6 \mathrm{mg} / \mathrm{kg}$.

Anesthesia was maintained with sevoflurane $2-3$ vol\% and a fraction of inspired oxygen 0.5 . Intraoperative hypotension (mean arterial pressure [MAP] $<65 \mathrm{mmHg}$ ) was treated with ephedrine 5 to $10 \mathrm{mg}$ or phenylephrine 20 to $40 \mu \mathrm{g}$. Intraoperative hypertension (MAP $>120 \mathrm{mmHg}$ ) was treated with perdipine $0.5 \mathrm{mg}$. For bradycardia (heart rate $<40$ beats $/ \mathrm{min}$ ), patients were given either 0.25 or $0.5 \mathrm{mg}$ of atropine, and they were dropped out from the study. For tachycardia (heart rate $>$ 110 beats/min), sevoflurane concentration was increased to 3.0 vol\% and $200 \mathrm{ml}$ crystalloids were loaded. If heart rate $>110$ beats/min persisted despite these measures, esmolol $10 \mathrm{mg}$ was administered.

After ureteroscopic removal of ureteral stone, a 6 Fr ureteral stent and 16 Fr urethral catheter were inserted, and fixed with adhesive tapes. For the reversal of rocuronium bromide, sugammadex (Bridion ${ }^{\mathrm{TM}}$, Merck Sharp and Dohme [MSD], Oss, The Netherlands) $2 \mathrm{mg} / \mathrm{kg}$ was administered. After the recovery of spontaneous ventilation and eye opening, LMA was removed and the patients were transported to the PACU.

Severity of CRBD was determined as 'none' if patients did not complain at all of CRBD, 'mild' if patients answered yes only when asked of CRBD, 'moderate' if patients themselves complained of CRBD before being asked but did not show a behavioral response, and 'severe' if patients themselves not only complained of CRBD but also showed behavioral responses such as shaking their arms and legs, shouting, trying to remove the catheter, etc. $[1,2,10,11]$. Postoperative pain was recorded using the numerical rating scale (NRS) score (0: no pain, 10: worst imaginable pain). The Incidence and severity of CRBD and pain NRS score were assessed by an anesthesiology resident when patients achieved a Ramsay sedation score of 1 or 2 in the PACU [12]. If severe CRBD was present or the pain NRS score was 4 or higher, pethidine $25 \mathrm{mg}$ was administered. Postoperative nausea and vomiting (PONV), dry mouth and intraoperative tachycardia (heart rate $>100$ beats/min) were also recorded. The primary endpoint is the incidence and severity of CRBD, and the secondary endpoints are the amount of analgesics requested, PONV after operation, and frequency of dry mouth.

Calculation of sample size was based on the results of a previous study performed by Kim et al. [7], in which the CRBD incidence was $89 \%$ when using atropine and $65 \%$ when using glycopyrrolate. Assuming that glycopyrrolate would reduce the incidence of CRBD by $20 \%$, power analysis with $\alpha=0.05$ and $1-\beta=0.8$ showed that a minimum of 35 patients were required in each group. The dropout rates were set to $20 \%$, and a total of 88 subjects, with 44 subjects in each group, were studied. Statistical analysis was performed using SPSS version 19.0 (IBM Corp., Armonk, NY, USA). Incidence of CRBD, PONV, dry mouth, intraoperative hypotension, hypertension, bradycardia, and tachycardia, and the number of patients administered with pethidine were compared by using the Chi-square test or 
Fisher's exact test (if cell size $\leq 5$ ). Postoperative pain NRS score was compared using the $\mathrm{t}$-test. $\mathrm{P}$ value $<0.05$ was regarded as statistically significant.

\section{Results}

Eighty-eight patients were enrolled in this study. Five patients were dropped out because of intraoperative anti-muscarinic drugs use (1 patient), and for not inserting a ureteral stent (4 patients). Therefore a total of 83 patients (control group $=43$, glycopyrrorate $=40$ ) were assessed in this study. There was no significant difference in demographic data between the two groups (Table 1).

Table 1. Demographic Data

\begin{tabular}{lcc}
\hline \multirow{2}{*}{\multicolumn{1}{c}{ Parameters }} & \multicolumn{2}{c}{ Group } \\
\cline { 2 - 3 } & $\begin{array}{c}\text { Control } \\
(\mathrm{n}=43)\end{array}$ & $\begin{array}{c}\text { Glycopyrrolate } \\
(\mathrm{n}=40)\end{array}$ \\
\hline Age $(\mathrm{yr})$ & $50.2 \pm 14.5$ & $48.6 \pm 12.2$ \\
Sex $(\mathrm{M} / \mathrm{F})$ & $33 / 10$ & $29 / 11$ \\
ASA classification (I/II) & $27 / 16$ & $23 / 17$ \\
Weight $(\mathrm{kg})$ & $70.2 \pm 11.0$ & $70.4 \pm 12.8$ \\
Height $(\mathrm{cm})$ & $167.2 \pm 8.2$ & $169.5 \pm 7.8$ \\
Duration of operation (min) & $23.0 \pm 15.9$ & $18.7 \pm 12.2$ \\
Duration of anesthesia (min) & $39.3 \pm 19.1$ & $37.9 \pm 13.1$
\end{tabular}

Data are presented as means \pm SD or the number of patients. There were no significant differences between the two groups. ASA: physical status of American Society of Anesthesiologists.
Total CRBD incidence was significantly lower in the glycopyrrolate group than in the control group $(65.0 \%$ vs. $95.3 \%$, relative risk $[R R]=0.68,95 \%$ confidence interval $[\mathrm{CI}]=0.53-0.86$, $\mathrm{P}=0.001$ ). The incidence of moderate to severe CRBD was also significantly lower in the glycopyrrolate group than in the control group ( $15.0 \%$ vs. $46.5 \%, \mathrm{RR}=0.32,95 \% \mathrm{CI}=0.14-0.72, \mathrm{P}=$ 0.002) (Table 2).

Median pain NRS score was lower in the glycopyrrolate group than in the control group $(1[0,2]$ vs. $3[1,5]$ as median [Q1, Q3], Hodges-Lehman median difference $=1.00,95 \% \mathrm{CI}$ $=0.00-2.00, \mathrm{P}=0.002)$. The number of patients administered postoperative pethidine was not significantly different between the glycopyrrolate and control group ( $22.5 \%$ vs. $44.2 \%, \mathrm{P}=0.084)$ (Table 2).

The incidence of intraoperative tachycardia was significantly higher in the glycopyrrolate group than in the control groups (30.0\% vs. 9.3\%, $\mathrm{RR}=3.22,95 \% \mathrm{CI}=1.13-9.18, \mathrm{P}=0.029$ ) (Table 3 ).

The incidence of PONV was not significantly different between the glycopyrrolate and control groups (7.5\% vs. $4.7 \%, \mathrm{P}$ $=0.665)$. The incidence of dry mouth was also not significantly different between the glycopyrrolate and control groups $(42.5 \%$ vs. $30.2 \%, \mathrm{P}=0.404$ ) (Table 3 ).

\section{Discussion}

In this study, the use of glycopyrrolate as a premedication during ureteroscopic removal of ureter stone decreased the inci-

Table 2. Incidence and Severity of Catheter-related Bladder Discomfort

\begin{tabular}{|c|c|c|c|c|c|}
\hline & $\begin{array}{l}\text { Control } \\
(\mathrm{n}=43)\end{array}$ & $\begin{array}{c}\text { Glycopyrrolate } \\
(\mathrm{n}=40)\end{array}$ & $\mathrm{RR}$ or $\mathrm{MD}$ & $95 \% \mathrm{CI}$ & $P$ value \\
\hline \multicolumn{6}{|l|}{ CRBD } \\
\hline Incidence & $41(95.3)$ & $26(65.0)$ & 0.68 & $0.53-0.86$ & 0.001 \\
\hline \multicolumn{6}{|l|}{ Severity } \\
\hline Mild & $21(48.8)$ & $20(50.0)$ & & & \\
\hline Moderate & $16(37.2)$ & $5(12.5)$ & & & \\
\hline Severe & $4(9.3)$ & $1(2.5)$ & & & \\
\hline Moderate to severe & $20(46.5)$ & $6(15.0)$ & 0.32 & $0.14-0.72$ & 0.002 \\
\hline Postoperative pain & $3[1,5]$ & $1[0,2]$ & 1.00 & $0.00-2.00$ & 0.002 \\
\hline Pethidine administration & $19(44.2)$ & $9(22.5)$ & & & 0.084 \\
\hline
\end{tabular}

Data are presented as median [Q1, Q3] or the number of patients (\%). P value $<0.05$ was statistically significant. CRBD: catheter-related bladder discomfort, Postoperative pain (NRS): numerical rating scale, RR: relative risk, MD: median difference, 95\% CI: $95 \%$ confidence interval.

Table 3. Incidence of Side-effects

\begin{tabular}{lcccc}
\hline \multicolumn{1}{c}{ Side-effects } & $\begin{array}{c}\text { Control } \\
(\mathrm{n}=43)\end{array}$ & $\begin{array}{c}\text { Glycopyrrolate } \\
(\mathrm{n}=40)\end{array}$ & RR & 95\% CI value \\
\hline Nausea and vomiting & $2(4.7)$ & $3(7.5)$ & & 0.665 \\
Supraventricular tachycardia & $0(0.0)$ & $0(0.0)$ & 3.22 & $1.13-9.18$ \\
Intraoperative tachycardia & $4(9.3)$ & $12(30.0)$ & & 0.029 \\
Dry mouth & $13(30.2)$ & $17(42.5)$ & \\
\hline
\end{tabular}

Data are presented as the number of patients (\%). P value $<0.05$ was statistically significant. RR: relative risk, $95 \%$ CI: $95 \%$ confidence interval. 
dence and severity of CRBD in the PACU, and reduced the pain NRS score.

After ureter stone removal, a ureteral stent and urethral catheter are inserted to prevent ureteric obstruction and remove residual stone fragments, which may cause postoperative CRBD [13]. Since CRBD can cause not only postoperative distress but also delirium in the PACU, it must be treated aggressively [6,14-16].

The muscarinic receptor has 5 subtypes (M1, M2, M3, M4, and M5). The M3 receptor is related to direct bladder contraction $[17,18]$, while the M2 receptor is associated with indirect bladder contraction by either enhancing the effect of M3 or by reversing the relaxation caused by a cyclic adenosine monophosphate induced beta-adrenergic stimulation [19]. Through M3 and M2, muscarinic receptors contract the smooth muscles around the bladder, which is one the main causes of CRBD.

In previous studies, tolterodine, oxybutynin, tramadol, and butylscopolamine $[1,2,4,20]$ which have an anti-muscarinic effect, and dexmedetomidine [5], especially specific in antimuscarinic M3 receptor, are known to be effective in preventing CRBD. Glycopyrrolate is also known to have high affinity to M3 receptor, which are related to smooth muscles $[17,18]$. However, there are few studies conducted on its usefulness as an M3 receptor antagonist. Recently glycopyrrolate as reversing agents of muscle relaxants was reported to be effective in reducing postoperative CRBD by Kim et al. [7]. Kim et al's study [7] used glycopyrrolate during anesthetic recovery, whereas this study used glycopyrrolate as a premedication.

According to the results of the present study, the relative risk of CRBD incidence was 0.68 times lower in the glycopryrrolate group than in the control group. This result displayed that the antagonistic effect of glycopyrrolate as premedications on preventing smooth muscle contraction and reducing CRBD lasted into recovery phases at the PACU.

In the recent study that used glycopyrrolate as a reversing agent by Kim et al. [7], CRBD incidence in the glycopyrrolate group was $65 \%$, which was similar to the result of this study, with CRBD incidence of $65 \%$. Comparing the two studies, there was no difference in CRBD incidence between the two glycopyrrolate groups. This seems to be due to glycopyrrolate's long duration of action (96 minutes or more) [17] and the persistence of drug efficacy in postoperative period. There was no difference in CRBD incidence according to the timing of glycopyrrolate administration. If one uses sugammadex to reverse muscle relaxation after ureteroscopy surgery, premedication with glycopyrrolate would be helpful in preventing CRBD in the PACU.
A recent study by Kim et al. [21] suggested a reduction in CRBD with sevoflurane use, and the study reported a CRBD frequency of $64 \%$ using sevoflurane during TURB surgery. However, atropine, an anti-muscarinic drug, was used for the reversal of muscle relaxants in the study during recovery from anesthesia. Atropine does not have high affinity for the M3 receptor subtype, but acts broadly on muscarinic receptors [22]. In this aspect, the study by Kim et al. [21] is different from the control group in the present study, in which anti-muscarinic drugs (e.g., atropine) were not used at all.

In this study, the incidence of CRBD in the control group was $95 \%$, which was relatively high compared to incidences in previous studies. The CRBD occurrence rate was $58-80 \%$ in studies that dealt with CRBD incidences due to urethral catheters [2-5], and was $70-80 \%$ in studies investigating irritative voiding symptoms in patients with ureteral stent insertion $[23,24]$. The high incidence of CRBD in this study may be due to the insertion of both a urethral catheter and ureteral stent in patients.

Tachycardia during operation occurred in 12 patients (30\%) in the glycopyrrolate group, greater than the 4 cases in the control group (9.3\%). There were 2 cases in which heart rate went up to 110 beats/min or more in the glycopyrrolate group. However, they did not show any complication during the operation. Nevertheless, glycopyrrolate must be carefully used especially if a patient has pre-existing medical conditions such as tachycardia, heart rate of over 100 beats/min, atrial fibrillation, or arrhythmia.

There are some limitations to this study. First, since CRBD was assessed in the PACU after patients were administered a single-dose of glycopyrrolate as premedication, whether glycopyrrolate reduced postoperative CRBD in a dose-response manner could not be identified. Second, CRBD was assessed only in the PACU after recovery from anesthesia. There were no followup assessments in hospital wards.

In conclusion, for patients receiving ureteroscopy under general anesthesia, glycopyrrolate premedication reduced postoperative CRBD incidence and severity without any serious side effects when sugammadex was used for neuromuscular blockade reversal.

\section{ORCID}

Jin Hye Min, http://orcid.org/0000-0002-0259-6501

Jin A Kim, http://orcid.org/0000-0002-7484-8667

\section{References}

1. Agarwal A, Raza M, Singhal V, Dhiraaj S, Kapoor R, Srivastava A, et al. The efficacy of tolterodine for prevention of catheter-related bladder 
discomfort: a prospective, randomized, placebo-controlled, double-blind study. Anesth Analg 2005; 101: 1065-7.

2. Agarwal A, Yadav G, Gupta D, Singh PK, Singh U. Evaluation of intra-operative tramadol for prevention of catheter-related bladder discomfort: a prospective, randomized, double-blind study. Br J Anaesth 2008; 101: 506-10.

3. Agarwal A, Dhiraaj S, Pawar S, Kapoor R, Gupta D, Singh PK. An evaluation of the efficacy of gabapentin for prevention of catheter-related bladder discomfort: a prospective, randomized, placebo-controlled, double-blind study. Anesth Analg 2007; 105: 1454-7.

4. Agarwal A, Dhiraaj S, Singhal V, Kapoor R, Tandon M. Comparison of efficacy of oxybutynin and tolterodine for prevention of catheter related bladder discomfort: a prospective, randomized, placebo-controlled, double-blind study. Br J Anaesth 2006; 96: 377-80.

5. Kim HC, Lee YH, Jeon YT, Hwang JW, Lim YJ, Park JE, et al. The effect of intraoperative dexmedetomidine on postoperative catheterrelated bladder discomfort in patients undergoing transurethral bladder tumour resection: a double-blind randomised study. Eur J Anaesthesiol 2015; 32: 596-601.

6. Kim HC, Kim E, Jeon YT, Hwang JW, Lim YJ, Seo JH. Postanaesthetic emergence agitation in adult patients after general anaesthesia for urological surgery. J Int Med Res 2015; 43: 226-35.

7. Kim HC, Lim SM, Seo H, Park HP. Effect of glycopyrrolate versus atropine coadministered with neostigmine for reversal of rocuronium on postoperative catheter-related bladder discomfort in patients undergoing transurethral resection of bladder tumor: a prospective randomized study. J Anesth 2015; 29: 831-5.

8. Guard BC, Wiltshire SJ. The effect of glycopyrrolate on postoperative pain and analgesic requirements following laparoscopic sterilisation. Anaesthesia 1996; 51: 1173-5.

9. Campos JH, Kernstine KH. A comparison of a left-sided Broncho-Cath with the torque control blocker univent and the wire-guided blocker. Anesth Analg 2003; 96: 283-9.

10. Agarwal A, Gupta D, Kumar M, Dhiraaj S, Tandon M, Singh PK. Ketamine for treatment of catheter related bladder discomfort: a prospective, randomized, placebo controlled and double blind study. Br J Anaesth 2006; 96: 587-9.

11. Bala I, Bharti N, Chaubey VK, Mandal AK. Efficacy of gabapentin for prevention of postoperative catheter-related bladder discomfort in patients undergoing transurethral resection of bladder tumor. Urology 2012; 79: 853-7.

12. Ramsay MA, Savege TM, Simpson BR, Goodwin R. Controlled sedation with alphaxalone-alphadolone. Br Med J 1974; 2: 656-9.

13. Ryan PC, Lennon GM, McLean PA, Fitzpatrick JM. The effects of acute and chronic JJ stent placement on upper urinary tract motility and calculus transit. Br J Urol 1994; 74: 434-9.

14. Tauzin-Fin P, Sesay M, Svartz L, Krol-Houdek MC, Maurette P. Sublingual oxybutynin reduces postoperative pain related to indwelling bladder catheter after radical retropubic prostatectomy. Br J Anaesth 2007; 99: 572-5.

15. Guenther U, Radtke FM. Delirium in the postanaesthesia period. Curr Opin Anaesthesiol 2011; 24: 670-5.

16. Lepousé C, Lautner CA, Liu L, Gomis P, Leon A. Emergence delirium in adults in the post-anaesthesia care unit. Br J Anaesth 2006; 96: 74753.

17. Haddad EB, Patel H, Keeling JE, Yacoub MH, Barnes PJ, Belvisi MG. Pharmacological characterization of the muscarinic receptor antagonist, glycopyrrolate, in human and guinea-pig airways. Br J Pharmacol 1999; 127: 413-20.

18. Eglen RM, Hegde SS, Watson N. Muscarinic receptor subtypes and smooth muscle function. Pharmacol Rev 1996; 48: 531-65.

19. Chess-Williams R. Muscarinic receptors of the urinary bladder: detrusor, urothelial and prejunctional. Auton Autacoid Pharmacol 2002; 22: 133-45.

20. Ryu JH, Hwang JW, Lee JW, Seo JH, Park HP, Oh AY, et al. Efficacy of butylscopolamine for the treatment of catheter-related bladder discomfort: a prospective, randomized, placebo-controlled, double-blind study. Br J Anaesth 2013; 111: 932-7.

21. Kim HC, Hong WP, Lim YJ, Park HP. The effect of sevoflurane versus desflurane on postoperative catheter-related bladder discomfort in patients undergoing transurethral excision of a bladder tumour: a randomized controlled trial. Can J Anaesth 2016; 63: 596-602.

22. Eglen RM, Watson N. Selective muscarinic receptor agonists and antagonists. Pharmacol Toxicol 1996; 78: 59-68.

23. Cheung MC, Lee F, Leung YL, Wong BB, Tam PC. A prospective randomized controlled trial on ureteral stenting after ureteroscopic holmium laser lithotripsy. J Urol 2003; 169: 1257-60.

24. Srivastava A, Gupta R, Kumar A, Kapoor R, Mandhani A. Routine stenting after ureteroscopy for distal ureteral calculi is unnecessary: results of a randomized controlled trial. J Endourol 2003; 17: 871-4. 